University of Texas Rio Grande Valley

ScholarWorks @ UTRGV

$11-2019$

\title{
Isabel M. Córdova, Pushing in Silence: Modernizing Puerto Rico and the Medicalization of Childbirth (Austin, TX: University of Texas Press, 2017), pp. 234, \$29.95, pb.
}

Rosalynn A. Vega

The University of Texas Rio Grande Valley, rosalynn.vega@utrgv.edu

Follow this and additional works at: https://scholarworks.utrgv.edu/anthro_fac

Part of the Anthropology Commons

\section{Recommended Citation}

Vega, R. (2019). Isabel M. Córdova, Pushing in Silence: Modernizing Puerto Rico and the Medicalization of Childbirth (Austin, TX: University of Texas Press, 2017), pp. 234, \$29.95, pb. Journal of Latin American Studies, 51(4), 978-980. doi:10.1017/S0022216X19001238

This Book Review is brought to you for free and open access by the College of Liberal Arts at ScholarWorks @ UTRGV. It has been accepted for inclusion in Anthropology Faculty Publications and Presentations by an authorized administrator of ScholarWorks @ UTRGV. For more information, please contact justin.white@utrgv.edu, william.flores01@utrgv.edu. 
Isabel M. Córdova, Pushing in Silence: Modernizing Puerto Rico and the Medicalization of Childbirth (Austin: University of Texas Press, 2017), pp. 234, \$29.95 pb.

Córdova documents a twenty-year transformation in how babies were born in Puerto Rico. In the middle of the twentieth century, Puerto Rico had twice as many midwives as registered doctors. At this time, birth was a home-based, family-oriented process that mothers accomplished with the assistance of midwives. By 1970, midwives had disappeared and the number of physicians tripled - a context that led to nearly every Puerto Rican baby (98\%) being delivered in a hospital under the authority of an obstetrician. In contrast to births a couple decades before, hospital-based births in the 1970s were highly medicalized and directed by predominantly male biomedical practitioners. Then, after the 1980s, doctors' fear of malpractice suits and corporate hospital concerns paved the way for a technocratic model of birth. In this corporate-legal framework, midwives were forced to recast themselves, or else face the disappearance of their profession. Pushing in Silence investigates the causes of these historical shifts with regards to Puerto Rican births, as well as the accompanying changes in attitude toward birthing, midwives, and doctors.

Specifically, Córdova explains how, as Puerto Rico's emerging populist government instituted new political, economic, and ideological structures, it also established itself as a colonial welfare system remaking itself according to rational, scientific planning and industrial modernization. The development of medical education (for example, the existence of a a federally accredited four-year medical school after 1950), new medical technologies, significant improvements to quality of life, and urbanization were all part and parcel to this transformation. Puerto Rico's new faith in science allowed physicians to assert themselves, 
Isabel M. Córdova, Pushing in Silence: Modernizing Puerto Rico and the Medicalization of Childbirth (Austin: University of Texas Press, 2017), pp. 234, \$29.95 pb.

thus moving the process of childbirth into the hospital, and redefining the practice of childbirth altogether.

Importantly, Córdova argues that birthing practices changed as a result of state-led industrialization, and that the expansion of the welfare state played a determining role in the medicalization of birth in Puerto Rico. Family life in Puerto Rico went from a predominantly private, rural space where the majority of individuals' basic needs were met within the home to a public, urban space in which consumer-oriented families were dependent on the state. This transformation paved the way for people to see the hospital as an acceptable place for not only birthing, but also for acquiring resources offered by the state. She writes, "The hospital became a familiar place of possibility where the government would coordinate and distribute welfare services." (175) In sum, her argument points to the close interrelatedness among economics, politics, and culture.

Córdova indicates that the medicalization of birth was not unilaterally imposed by those in power. Instead, it resulted as part of a society-wide embrace of "progress" and "modernity." During the transition, women had increasing access to education, science, technology, and urban spaces. Medical knowledge became standardized, thus redefining ideas about what is "normal." Furthermore, as the middle class grew, the life styles of midwives and prospective mothers also underwent transformation. In essence, Córdova argues that studying births serves as a lens for understanding Puerto Rico's core value systems, and, specifically, its supervaluation of science, objectivity, positivist truths, and reductionist practices during the second half of the twentieth century. Interestingly, this desire for progress and science is 
Isabel M. Córdova, Pushing in Silence: Modernizing Puerto Rico and the Medicalization of Childbirth (Austin: University of Texas Press, 2017), pp. 234, \$29.95 pb.

indicative of Puerto Rico's admiration of the United States and ongoing aspirations regarding their relationship to the mainland.

The book is primarily comprised of Córdova's analysis of primary sources, including government documents, newspaper articles, and medical publications. However, to "flesh out" her arguments, Córdova derives stories from thirty interviews completed in Puerto Rico between 2002 and 2007. The ethnographic element of Córdova's research methods gives her writing greater sensitivity to the stratified nature of reproduction, and specifically, that the ways women give birth vary based on class, gender, and geographic space. As a result, Pushing in Silence reveals overall trends and local nuances. In this vein, Córdova remarks, "these microstudies remind us that historical events rarely, if ever, unfold at a consistent and equal pace." (14)

Córdova's arguments regarding Puerto Rican birthing are rooted in feminist theories of medicine, science, and epistemology. Central to her historic narrative are the medical divisions of labor, the production of scientific knowledge, and the resulting devaluation of women's skills and legitimacy within the realm of birth. As such, Pushing in Silence, lays bare competing notions of women's bodies. The earlier notion portrayed women's bodies as imbued with the natural ability to give life (i.e. "built to give birth"). The subsequent notion cast feminine biology as inherently defective, insufficient without medical intervention, and susceptible to risk and chaos. 
Isabel M. Córdova, Pushing in Silence: Modernizing Puerto Rico and the Medicalization of Childbirth (Austin: University of Texas Press, 2017), pp. 234, \$29.95 pb.

Intriguingly (and sadly), Córdova asserts that the more recent rise in cesarean sections is a consequence of "defensive medicine" - that is, doctors practicing in a tense atmosphere and reacting to constant fear of lawsuits. The litigious context framing obstetrics has caused medical students to turn away from obstetrics as a speciality, and for some obstetricians to even abandon their practice. Given this backdrop, Córdova explains, "These surgeries made patients feel they had obtained the best medical care possible, and, oddly enough, left doctors believing they would be less vulnerable to lawsuits." (176) This situation has left birth in Puerto Rico ripe with possibility: Córdova indicates that in the new millennium, women may respond to high cesarean rates by once again turning to midwife-assisted birth. Her prediction is bolstered by a 2007 Puerto Rico Department of Health initiative to send nurse-midwives to more remote areas of Puerto Rico where women have less access to obstetrical services. She closes her book with this provocative affirmation: "Ten years into the new millennium there were many reasons to believe that childbirth in Puerto Rico, as well as in the United States, was reaching new crossroads." (180)

Pushing in Silence is an accessible monography, appropriate for readers interested in the history of midwives; general medical education and obstetrics; birth practices, laws, and models; trends in general health statistics; and political, social, and economic development in Puerto Rico.

ROSALYNN A. VEGA University of Texas Rio Grande Valley 